\title{
Margin requirements and stock market volatility in Bangladesh
}

\author{
A. F. M. Mainul Ahsan \\ Department of Economics, School of Business, \\ Independent University, Bangladesh (IUB), Dhaka, Bangladesh \\ Mohammad Osman Gani \\ Department of Economics, School of Business, \\ Independent University, Bangladesh (IUB), Dhaka, Bangladesh
}

Md. Bokhtiar Hasan

Research, Development \& Information Department

Dhaka Stock Exchange Limited, Dhaka, Bangladesh

\begin{abstract}
Officially margin requirements in bourses in Bangladesh were initiated on April 28, 1999, to limit the amount of credit available for the purpose of buying stocks. The goal of this paper is to measure the impact of changing margin requirement on stock returns' volatility in Dhaka Stock Exchange (DSE). The impact of margin requirement on stock price volatility has been extensively studied with mixed and ambiguous results. Using daily stock returns, we found mixed evidence that SEC's margin requirements have significant impact on market volatility in DSE.
\end{abstract}

Key Words : Margin, Requirements, Volatility, Stock Market

\section{Introduction}

Margin requirement can be defined as the amount that an investor must deposit in order to open or maintain a position in stocks and derivatives. A margin loan is secured by the client's collateral which is a portfolio of securities and typically carries a margin rate (the interest charged on the loan) that is favorable due to the presence of collateral. Moore (1966) and Figlewski (1984) explain reasons for implementing margin requirement. The first rationale is to ensure credit and resources are allocated to productive economic activities that are not including speculation activities. The second is to check investors from taking awfully high leverages which may eventually be detrimental to them. The third is to lessen the risk of price movements which is driven by purchasing stock on credit. To meet these goals, however, it is assumed that an investor will not seek ways to obtain credit to finance their stock purchases other than borrowing through margin account.

The Securities Act of 1934 gave the Federal Reserve the right to control initial margin requirements ratio (MRR) in the U.S. for the purpose of limiting the amount of credit that is used in buying or carrying securities. Since October 1, 1934, MRR has been changed 22 times. The margin requirement has been fixed at $50 \%$ since January 3,1974 , i.e., the Fed left the MRR unchanged for the last 38 years, even when looming market bubbles turned into crashes, in order to avoid making the crashes more debilitating. On contrary, during the period between January 17, 2010 and January 10, 2011, the Securities and Exchange Commission (SEC) in Bangladesh put in 83 directives and changed the directives of margin loan ratio 19 times. On February 1, 2010, the SEC set the margin 
ratio to 1:1.5. Again, on February $3^{\text {rd }}, 2010$, SEC revised its margin ratio to $1: 1$ effecting from February $7^{\text {th }}$, 2010. Then within a month, on March $15^{\text {th }}, 2010$, the Commission changed the margin ratio again to 1:1.5 effecting from March 18, 2010.

The impact of margin requirement on stock price volatility has been extensively studied with mixed and ambiguous results. But the Bangladesh experience has been overlooked. The nascent stock market in Bangladesh may offer glimpses into how a newly developing economy may deal with the stock market.

The ambiguity of the previous studies for developed markets is not surprising. There is no compelling reason to expect margin requirement to have definite effects on stock prices or returns. Only if investors do take higher risk with borrowed funds than with their own equity then the margin requirement may have effect on the volatility. There is no clear evidence or indeed much theoretical discussion on the risk bearing propensity of investors.

The picture is further compounded by a distinction between regular investors who hold stocks for the long haul and care primarily about the dividend, and the speculators who trade in stocks for arbitrage through capital gains in the short run. There is no reason to expect that these two groups have the same risk bearing propensities.

Even more astonishingly, there has been very little systemic study on the importance of the stock market in the capital market. In case of Bangladesh, the stock market capital represents perhaps less than one fourth of one percent of the nation's physical capital. It should have no significant effect the performance of the economy one way or another. The big problem however is the potentially unsafe exposure of the financial sector to the volatile stock market. There is practically no information on the extent of exposure to stock market risk.
However, after a massive nosedive such as the one that occurred recently in the Bangladeshi stock market, there is renewed urgency to look at the margin requirement and other available tools to calm down the highly volatile market and to assure the nervous investors. This paper looks at the evidence from Bangladesh. The results may give some comfort to the regulators that they may use margin requirements to stabilize the market. However, there may be more potent tools to develop an investment climate with greater stability and more diversified options for investment.

Using data from December 2004 to January 2011 and DGEN index, we found mixed result about relation between margin requirements and return volatility in Dhaka Stock Exchange (DSE), Bangladesh. Rest of paper is divided in to four parts. Part 2 will discuss about previous studies on this issue. Part 3 will talk about margin structure in context of Bangladesh. Part 4 will focus on data and methodology used in this paper. Part 5 will briefly analyze results of this research.

\section{Literature review on stock price volatility}

This brief review of the literature has two parts. The first part deals with the specific relation between margin requirements and stock price volatility. The second part sees this extremely narrow issue in a broader context so that the relation can be made meaningful.

\section{Relation between margin requirement and stock price volatility}

Hardouvelis (1988) concludes that higher initial margin requirements in the cash market are statistically associated with a reduction both actual and excess stock price volatility. An increase in margin requirement does reduce volatility.

Hardouvelis and Peristiani (1990) examined the Japanese evidence to find significant impact of margin requirements. They think that margin requirements may be an effective tool. 
Hardouvelis and Theodossiou (2002) found that higher initial margin requirements are associated with lower subsequent stock market volatility in normal and bull periods but not in bear runs. Higher margins are also negatively related to conditional mean of stock returns.

Ricke (2003) develops an analytical model to conclude that margin loans can cause bubbles, the level of margin loans as well as initial margin requirements may affect asset prices, and, a properly set initial margin may prevent bubbles.

French, Schwert and Stambaugh (1987) examined the relation between stock returns and stock market volatility. They found evidence that the expected market risk premium (the expected return on a stock portfolio minus the Treasury bill yield) is positively related to the predictable volatility of stock returns. There is also evidence that unexpected stock market returns are negatively related to the unexpected change in the volatility of stock returns. This negative relation provides indirect evidence of a positive relation between expected risk premiums and volatility.

Chowdhury (1997) finds statistically significant impact of margin requirements on the stock prices in Thailand. However, there is asymmetry. The market reacts strongly and immediately after a decrease, but the response to an increase in slower and weaker.

Kupiec and Sharpe (1991) show that imposing a binding initial margin requirement may either increase or decrease stock price volatility, depending upon the microeconomic structure behind fluctuations in economy-wide average risk-hearing propensity. The ambiguous effect on volatility similarly arises when the source of heterogeneity is noise trader beliefs. Important: Since dividend realizations contain no information about future returns, the risky asset price fluctuates only because of changes in taste for risk.
Schwert (1989) found no evidence that changes in margin requirements reduce subsequent stock return volatility. Also, trading halts have not had much effect on volatility in the past. Trading halts that were associated with banking panics were associated with high stock return volatility, but halts without bank panics were not associated with high levels of volatility.

Hsieh and Miller (1990) used daily and monthly stock returns and found no convincing evidence that margin requirements have served to dampen stock market volatility. The contrary conclusion, expressed in recent papers by Hardouvelis (1988), was traced to flaws in his test design. We do detect the expected negative relation between margin requirements and the amount of margin credit outstanding. We also confirm the recent finding by Schwert (1988) that changes in margin requirements by the Fed have tended to follow rather than lead changes in market volatility.

Fortune (2001) claims that despite the statistical significance of the margin loans to both mean stock returns and their volatility, the economic significance is so low that there is no support for using margin policy as a tool of any significant impact.

Kim and Oppenheimer (2002) considered the possibility that margins primarily affect individuals who, as a group, are believed to be the investors most affected when margin requirements change. Their empirical tests did not support this contention.

Lee (2009) finds no evidence that the margin tool is effective in controlling volatility in Canada.

Salinger (1989) finds that post-war US data provide no evidence of a link between the initial margin requirements and stock market volatility. Over the entire period in which the Federal Reserve has set margin requirements (1934-present), there is a correlation between margin requirements and margin debt on the one hand and volatility on the 
other. However, margin debt is not primarily associated with downside volatility and margin requirements are not primarily associated with upside volatility, as would be expected if margin buying were the cause of the volatility.

Lee and Yoo (1993) examined the effects of margin requirements on stock market volatility in the U. S., Japan, Korea, and Taiwan. Only Japan showed short-term significant relationship between margins and volatility. They showed that the margin effect on volatility is dominated by a liquidity effect rather than a speculative effect. Finally, they find no convincing evidence that margins affect volatility in the long-run, but instead find that volatility Granger causes margins.

Hsu (1996) examines Taiwan's experience with category A and Category B stocks. Category A stocks must maintain higher profitability and larger capital. Regulators probably think that category $B$ stocks are more risky and hence set higher margins for them. There is significant short run relation between margin requirements and volatility. However, there is some suspicion that margin changes Granger-cause volatility. The more speculative stocks are affected by margins.

\section{Making sense of stock market volatility}

To understand the ambiguity of the relationship between margin requirements and stock market volatility, it is worth raising broader issues to set the context in which this relation could be meaningful.

The first question is whether the stock prices behave differently than prices of other goods, services and especially other types of financial assets. What is peculiar to the price setting of stocks that would call for special investigation? There is no known attempt to bring the behavior of stock prices within the broader frame of price theory.
The issue of motivation behind the studies on stock market volatility remains unclear. Does the stock market represent any significant fraction of a nation's capital? At least for Bangladesh, it represents next to nothing and cannot be of any significance. But it generates data and the media thrives on reporting the slightest tremor in it. Whether this is merely a tempest in a teacup remains to be understood.

Indeed, prices of all things subject to gambling must be volatile specifically because gambler $s$ thrives on volatility. They abhor predictability. Behavioral economics ought to look at gambling behavior. In this respect, Schoemaker (1993) examines various concepts of risk-taking and concludes that it is perhaps an intractable concept.

Then there is a question of distinguishing and characterizing risk taking by entrepreneurs. Brockhaus (1980) says that the risk taking propensity may not be a distinguishing characteristic of entrepreneurs.

The issue needs further clarification. The risk-taking propensities of those who hold stocks for the longer run and care primarily about dividends ought to be distinguished from the risk-bearing propensities of those who thrive on short run price movements for capital gains. Indeed, futures, options and hedge funds thrive on expectations of volatility.

Bucciol Miniaci (2012) compare alternative measures of risk, based on a financial portfolio or based on a broader portfolio also including human capital, real estate, business wealth and related debt. The measures provide a different ranking of household risk bearing, but they consistently show that risk bearing fell in the 2000s, and it positively correlates with wealth, good health status and financial sophistication. Furthermore, the time effect seems more relevant than the cohort effect, and the risk-age profile looks flat over the life-cycle. 
Busche and Hall (1988) find that Hong Kong bettors seem to be either risk neutral or risk averse, while other studies of North American bettors showed the opposite result.

Harlow and Brown (1990) obtained risk-aversion estimates experimentally from observations of bidding behavior in computerized auctions using newly developed theoretical models. These measures were then compared with a psychometric assessment of "sensation-seeking" personality traits and with measures of neurochemical activity that have previously been found to be significantly related to human behavior. Individuals with neurochemical activity characterized by lower levels of the enzyme monoamine oxidize and with a higher degree of sensation-seeking are more willing to accept economic risk.

The analytical issues of conceptual clarity remains unexplored This is a major gap that cries out for attention. The stock market behavior is not open to meaningful interpretation in the presence the major gaps in knowledge about its context in the economy.

\section{Margin in Bangladesh}

Though in the U.S., and in many other countries, margin requirement is set by the Central Bank, in Bangladesh, like India, Securities and Exchange Commission (SEC) decides the margin ratio. In Bangladesh, two types of margin loan exist. One is for investors and another is for members of the stock exchange.

\section{Margin for investors}

Before April 28, 1999, in Bangladesh, members or brokers were not permitted to provide credit facilities to their clients. However, unofficially or informally they did provide credit facilities to their clients which were totally unauthorized. Both the Exchanges and Commission detected it and observed that it was perturbing the market and also realized that it could lead the market into more trouble provided that there were no guidelines or rules for margin loan facilities. But it should be noted here that under SEC (Merchant Bank \& Portfolio Managers) Ordinance, 1996, some merchant banks, Investment Corporation of Bangladesh (ICB) operated some margin loan activities. But there was no specific ratio for margin loan before October 24, 2007. On October 23, 2007, under a notification, SEC fixed the margin ratio at 1:1 basis for merchant banks and portfolio managers.

Nonetheless, in exercise of the powers conferred by Section 33 of the Securities and Exchange Ordinance, 1969 (Ordinance No. XVII of 1969), the Securities and Exchange Commission made the Margin Rules, 1999 on April 28, 1999. Under these rules, a member can extend facilities to the clients for the purpose of securities transactions subject to the margin account requirements of these rules. Margin account must be evidenced in the form of a written agreement executed between the member and the client.

According to the Margin Rules, 1999, the margin deposited by client with the member is required to be in the form of:

- Irrevocable and Without Resource to the Drawer Bank or Insurance Guarantee or Guarantee issued by the non-banking financial institution (NBFI) registered with the Bangladesh Bank provided such NBFI is lawfully authorized in this behalf;

- Government securities;

- Fixed Deposit Receipt issued by any scheduled bank;

- Sanchay Patra and Defense Saving Certificate issued by the Government of Bangladesh;

- Life Insurance Policy at surrender value;

- Demand Draft or Payment Order issued by any scheduled bank;

- Securities listed with the Exchange (valued at seventy percent of the lowest market price prevailed in the Exchange in the previous week); and

- Cash. 
Table 1 : Historical Margin requirement Changes in Bangladesh

\begin{tabular}{|c|c|c|}
\hline Date & Effective From & $\begin{array}{c}\text { Margin } \\
\text { Requirement }\end{array}$ \\
\hline 10 January, 2011 & 11 January, 2011 & $33.33 \%$ \\
\hline 19 December, 2010 & 20 December, 2010 & $40.00 \%$ \\
\hline December, 2010 & Immediate Effect & $50.00 \%$ \\
\hline 21 November, 2010 & 22 November, 2010 & $66.67 \%$ \\
\hline 8 July, 2010 & 11 July, 2010 & $50.00 \%$ \\
\hline 15 March, 2010 & 18 March, 2010 & $40.00 \%$ \\
\hline 3 February, 2010 & 7 February, 2010 & $50.00 \%$ \\
\hline 1 February, 2010 & Immediate Effect & $40.00 \%$ \\
\hline 3 February, 2008 & 10 February, 2008 & $50.00 \%$ \\
\hline 25 November, 2007 & 26 November, 2007 & $66.67 \%$ \\
\hline 19 November, 2007 & 20 November, 2007 & $100.00 \%$ \\
\hline 23 October, 2007 & 24 October, 2007 & $50.00 \%$ \\
\hline 18 April, 2005 & 19 April, 2005 & $33.33 \%$ \\
\hline 21 December, 2004 & Immediate effect & $100.00 \%$ \\
\hline 28 April, 1999 & & $33.33 \%$ \\
\hline
\end{tabular}

\section{Member's margin}

In exercise of the powers conferred by section 34(1) of the Securities and Exchange Ordinance, 1969 (Ordinance No. XVII of 1969), the Dhaka Stock Exchange Limited made the Dhaka Stock Exchange (Member's Margin) Regulations, 2000, with the approval of the Securities and Exchange Commission. According to these Regulations, "Member's margin" means the margin deposited by a member with the clearing house. Every member compulsorily deposited an amount as security deposit with the Exchange prescribed by the Exchange. Every member shall, in addition to the security deposit, deposit with the clearing house, free of interest, as member's margin an amount at the rate specified in subregulation (3) on his additional trade exposure within one hour of his exceeding the free limit failing which his trade shall remain suspended.

As per SEC directive (SCE/CMRRCD/2001-49/231 dated November 26, 2009), the free limit shall be five taka crore only in respect of the stock exchange members' margin deposit with the stock exchange on each trading day based on the total buy exposure, without linking to the capital requirements. However, members are changed heavily for additional trade exposures. 
However, this paper focuses only on the margin requirements for investors. Members' margin is irrelevant to this study. Table one illustrates historical margin requirement changes in Bangladesh. Currently, margin requirement is 33.33 percent.

\section{Data and methodology}

In Bangladesh, margin requirement was first changed on December 21, 2004. We used DSE General Index (DGEN) return for sample period December 2004 to January 2011. DGEN index includes all stock except $Z$ category firms. Securities and Exchange Commission in Bangladesh frequently cancelled margin facilities on $Z$ category stocks. We first tried to observe the return pattern associated with change in margin change. However, the main objective of this thesis is to measure the impact of margin requirement on returns' volatility. To that end, we used a regression model and also a variance ratio test to compare preand post-change in margin volatility.

\section{Variance ratio test}

For each margin requirement change, we determine a pre- and post-volatility in the DGEN Index. The pre (post) period corresponds to a window covering 60 trading days before (after) the announcement of the margin change. We compute the variance of daily returns for each of these windows separately. We then compute the ratio of these variances for each observation. The variance ratio is computed as follows:

$$
V R_{i}=\frac{\sigma_{i, p r e}^{2}}{\sigma_{i, p o s t}^{2}}
$$

$$
\begin{aligned}
& \text { Where, } \quad \sigma_{i, p r e}^{2}=\frac{\sum_{t=1}^{n_{i, p r e}}\left(r_{i, p r e, t}-\bar{r}_{i, p r \varepsilon}\right)^{2}}{n_{i, p r e}} \\
& \sigma_{i, p o s t}^{2}=\frac{\sum_{t=1}^{n_{i, p o s t}}\left(r_{i, p o s t, t}-\bar{r}_{i, p o s t}\right)^{2}}{n_{i, p o s t}} \\
& \bar{r}_{i, p r e}=\frac{\sum_{t=1}^{n_{i, p r e}} r_{i, p r e, t}}{n_{i, p r e}}
\end{aligned}
$$

$$
\bar{r}_{i, p o s t}=\frac{\sum_{t=1}^{n_{i, p o s t}} r_{i, p o s t, t}}{n_{i, p o s t}}
$$

$r_{i, p r e, t}$ is the return for observation $i$ on day $t$ during the pre-announcement period. $r_{i, p o s t, t}$ is read similarly. $n_{i, p r e}$ is the number of daily returns of an observation before the change in margin requirement. $n_{i, p o s t}$ is read similarly. This variance ratio will be tested for statistical significance at a level of $5 \%$ in comparison with the critical value of $F_{n_{i, p r g}}-1 n_{i, p o s t}-1$.

The null hypothesis is that the variance of returns is the same in the pre- and post-margin change periods. If margin requirement changes do not impact volatility, then one should expect the ratio not to be significantly higher or lower than one. Therefore, we test whether the variance ratio is different from one. Under regular conditions, the variance ratio follows an F-distribution. These conditions include normally distributed returns and independence between the numerator and the denominator of the variance ratio.

\section{Regression analysis}

The effective margin requirement is defined as the combination of the ratio of the initial margin requirement and cash-only deposit to the loan value. Effective margin requirement is calculated using the following formula employed by Hardouvelis (1991).

$$
M_{t}=100\left(1.5 \frac{C_{t}}{L_{t}}+\frac{\left(M_{t}^{0}-C_{t}\right)}{L_{t}}\right)
$$

Where $M_{t}$ is the effective margin requirement in the period of margin change, $C_{t}$ is the cash-only requirement in the period of margin change, $M_{t}^{0}$ is the official margin requirement in the period of margin change, $L_{t}$ is the loan value of stocks in the period of margin change. A value of 1.5 in the first term of the equation reflects the extra opportunity cost associated with the cash-only deposits. For example, currently margin loan ratio in Bangladesh 
is $1: 2$ which leads official margin requirements to $33.33 \%$. If the cash-only deposit is $10 \%$ while the loan value is $80 \%$, then the effective margin requirement will be 47.91 percent. However, in case of Bangladesh, effective margin requirement, , equals the official margin requirement, because there is no restriction to cash-only deposits. Based upon the definition of the effective margin requirement, we examine the short-term relation between margins and volatility using the following equation:

$$
\begin{gathered}
\Delta \boldsymbol{\sigma}_{\mathrm{i}}=\alpha+\alpha_{1} \Delta \mathbf{M}_{\mathrm{i}}+\boldsymbol{\alpha}_{2} \Delta \mathbf{R}_{\mathrm{i}}+\mu_{\mathrm{i}} \\
\text { Here, } \Delta \sigma=\sigma_{\mathrm{A}}-\sigma_{\mathrm{B}} \\
\Delta \mathrm{R}=\mathrm{R}_{\mathrm{A}}-\mathrm{R}_{\mathrm{B}} \\
\Delta \mathrm{M}=\mathrm{M}_{\mathrm{A}}-\mathrm{M}_{\mathrm{B}}
\end{gathered}
$$

$\mathrm{R}_{\mathrm{A}}=$ Geometric daily return from the business day before margin change to twenty-four business days after margin change (in percent);

$R_{B}=$ Geometric daily return from twenty four business days before margin change to the business day before margin change (in percent);

$M_{A}=$ Average margin level in the twenty four business day period before margin change (in percent); and

$M_{B}=$ Average margin level in the twenty four business day period after margin change (in percent).

The level of volatility is measured by the standard deviation of stock returns for each interval, while stock returns are included as the control variable for the effects of market level on volatility. Hardouvelis and Peristiani (1991) point out that it is likely to observe a spurious positive relation between margins and volatility since volatility is low during a bullish market and high during a bearish market and that stock prices are high before margin increases and low thereafter. The presence of such a relationship implies that in our regressions of volatility on margins, we must control for the size of stock returns.

\section{Result analysis}

Using data for sample period December 2004 to January 2011, column 2 in Table 2 shows the performance of stock prices before and after a raise in margin requirements; column 3 repeats the same analysis for a margin cut. Following the methodology applied in Hardouvelis and Peristiani (1989/90, 1992), Table 4 illustrates, for each business day, the total return excluding dividends - average geometric daily capital gain or loss - obtained by investors who buy the portfolio of stocks in the DSE General Index (DGEN) on the $15^{\text {th }}$ business day before the margin change and subsequently sell the same portfolio of stocks after business days $(=1, \ldots, 40)$. The return of a business day is estimated as the arithmetic average of individual returns across the 6 past margin increases (column 2) or the 8 past margin decrease (column 3). In calculating returns, dividend information was dropped. Average return data in column 2 and column 3 was graphed in Figure 1 and figure 2 respectively.

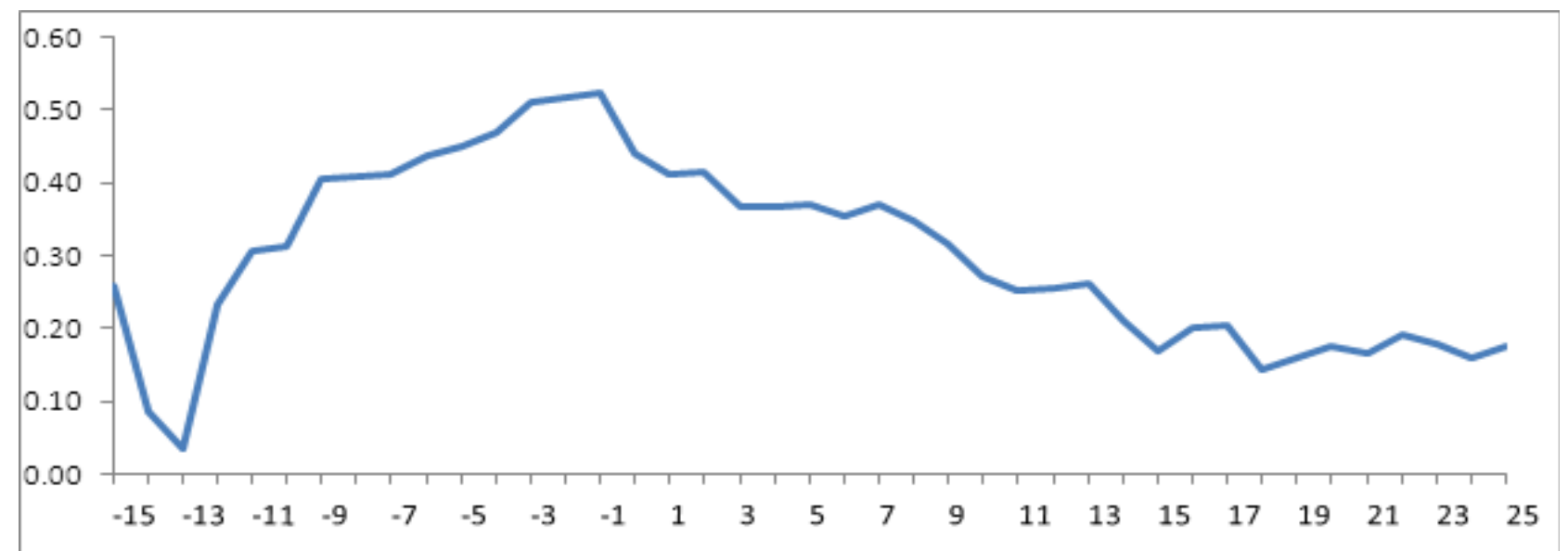

Figure 1: Stock Prices in Bangladesh before and after an Increase in Margin Requirement 


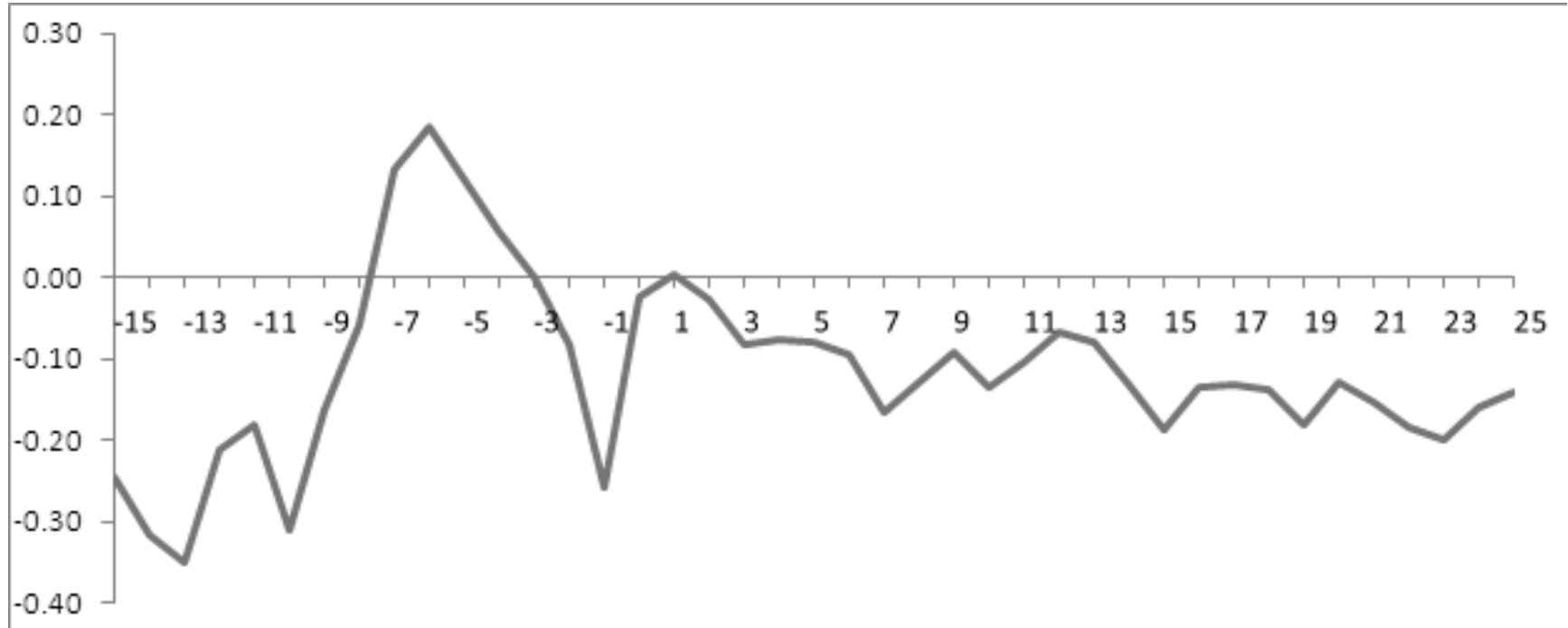

Figure 2: Stock Prices in Bangladesh before and after a Decrease in Margin Requirement

Column 2 in Table 2 reveals that margin requirement increases following a period of rising stock prices. Once the higher margin requirement becomes effective, the market demonstrates a slow declining trend. Column 3 reveals that margin requirements decline long after the market falls and that after the decrease in margin requirements, stock prices continue to increase. Overall, the evidence is consistent with an interpretation that margin requirements affect the movement of the market in the desired direction.

Table 2 : DGEN Index Mean Geometric Returns from 15 days before to 25 Days after the Margin Requirement Change

\begin{tabular}{|c|c|c|}
\hline $\begin{array}{c}\text { Number of } \\
\text { Days from MR } \\
\text { Change }\end{array}$ & $\begin{array}{c}\text { Average Return } \\
\text { When MR Increased }\end{array}$ & $\begin{array}{c}\text { Average Return } \\
\text { When MR Decreased }\end{array}$ \\
\hline-15 & 0.2577 & -0.2464 \\
\hline-14 & 0.0867 & -0.3175 \\
\hline-13 & 0.0362 & -0.3508 \\
\hline-12 & 0.2323 & -0.2126 \\
\hline-11 & 0.3064 & -0.1795 \\
\hline-10 & 0.3137 & -0.3087 \\
\hline-9 & 0.4044 & -0.1619 \\
\hline-8 & 0.4095 & -0.0563 \\
\hline-7 & 0.4115 & 0.1342 \\
\hline
\end{tabular}




\begin{tabular}{|c|c|c|}
\hline-6 & 0.4384 & 0.1840 \\
\hline-5 & 0.4489 & 0.1213 \\
\hline-4 & 0.4679 & 0.0566 \\
\hline-3 & 0.5111 & 0.0013 \\
\hline-2 & 0.5186 & -0.0818 \\
\hline-1 & 0.5240 & -0.2576 \\
\hline 0 & 0.4415 & -0.0224 \\
\hline 1 & 0.4121 & 0.0042 \\
\hline 2 & 0.4145 & -0.0263 \\
\hline 3 & 0.3686 & -0.0825 \\
\hline 4 & 0.3678 & -0.0759 \\
\hline 5 & 0.3691 & -0.0789 \\
\hline 6 & 0.3551 & -0.0942 \\
\hline 7 & 0.3717 & -0.1658 \\
\hline 8 & 0.3476 & -0.1278 \\
\hline 9 & 0.3169 & -0.0902 \\
\hline 10 & 0.2709 & -0.1342 \\
\hline 11 & 0.2530 & -0.1024 \\
\hline 12 & 0.2562 & -0.0677 \\
\hline 13 & 0.2606 & -0.0784 \\
\hline 14 & 0.2098 & -0.1310 \\
\hline 15 & 0.1703 & -0.1876 \\
\hline 16 & 0.2005 & -0.1340 \\
\hline 17 & 0.2051 & -0.1301 \\
\hline 18 & 0.1450 & -0.1392 \\
\hline 19 & 0.1608 & -0.1796 \\
\hline 20 & 0.1756 & -0.1282 \\
\hline 21 & 0.1670 & -0.1528 \\
\hline 22 & 0.1907 & -0.1828 \\
\hline 23 & 0.1783 & -0.1990 \\
\hline 24 & 0.1588 & -0.1586 \\
\hline 25 & 0.1759 & -0.1406 \\
\hline
\end{tabular}


When variance ratio (pre/post) is significantly less than 1 , we read this as supporting the margin requirement as a tool to reduce volatility. Inversely, when variance ratio is significantly greater than or equal to 1 , we infer this as not supporting the stated hypothesis. All individual tests use a significance level of $5 \%$. In all the 14 cases, i.e., both for margin increase and decrease, variance ratio is less than 1 (Table 3) which can be interpreted that margin requirement was used successfully to reduce volatility in Dhaka Stock Exchange in Bangladesh.

Table 3 : Result of Variance Ratio Test

\begin{tabular}{|l|l|}
\hline \multicolumn{1}{|c|}{ Date } & Variance Ratio Test \\
\hline 11 January, 2011 & 0.6559 \\
\hline 20 December, 2010 & 0.0000 \\
\hline 13 December, 2010 & 0.0000 \\
\hline 22 November, 2010 & 0.0000 \\
\hline 11 July, 2010 & 0.8119 \\
\hline 18 March, 2010 & 0.2120 \\
\hline 7 February,2010 & 0.1618 \\
\hline 1 February, 2010 & 0.3061 \\
\hline 10 February, 2008 & 0.5348 \\
\hline 26 November, 2007 & 0.9076 \\
\hline 20 November, 2007 & 0.2036 \\
\hline 24 October, 2007 & 0.4780 \\
\hline 19 April, 2005 & 0.0000 \\
\hline 21 December, 2004 & 0.0000 \\
\hline
\end{tabular}

Our result from the regression model conflicts with the results from the variance ratio test. Table 4 show illustrates the effect of margin requirement on return volatility for all the changes in margin requirements. Table $4(\mathrm{~A})$ and Table 4(B) do the same analysis for increase and decrease in margin requirement. None of the results from regression analysis shows that change in margin requirements in Dhaka Stock Exchange (DSE) have statistically significant effect on increasing or decreasing market volatility. These results clearly conflict with results from the variance ratio test. 
Table 4 : The Effect of Margin Requirements on Volatility - Total Margin Changes

\begin{tabular}{|c|c|c|c|}
\hline & \multicolumn{3}{|c|}{ Dependent Variable: Volatility } \\
\hline & 5-Day Interval & 10-Day Interval & 25-Day Interval \\
\hline $\begin{array}{c}\text { Independent } \\
\text { Variable: }\end{array}$ & & & \\
\hline Constant & $0.768085(0.0125)^{* *}$ & $0.750139(0.0062)^{* * *}$ & $0.676462(0.0048)^{* * *}$ \\
\hline$\Delta \mathbf{M}$ & $0.00181553(0.8434)$ & $-0.00540957(0.4421)$ & $0.000989779(0.8730)$ \\
\hline$\Delta \mathbf{R}$ & $0.727062(0.0105)^{* *}$ & $1.00164(0.0101)^{* *}$ & $1.01128(0.0266)^{* *}$ \\
\hline $\mathbf{R}^{2}$ & 0.502619 & 0.509659 & 0.430111 \\
\hline Sample & 14 & 14 & 14 \\
\hline
\end{tabular}

Table 4(A) : The Effect of Margin Requirements on Volatility - Margin Increases

\begin{tabular}{|c|c|c|c|}
\hline & \multicolumn{3}{|c|}{ Dependent Variable: Volatility } \\
\hline & 5-Day Interval & 10-Day Interval & 25-Day Interval \\
\hline $\begin{array}{c}\text { Independent } \\
\text { Variable: }\end{array}$ & & & \\
\hline Constant & $-0.365148(0.3692)$ & $0.405736(0.2373)$ & $0.0195910(0.9521)$ \\
\hline$\Delta \mathbf{M}$ & $0.00952925(0.2089)$ & $-0.00710888(0.2479)$ & $0.000393515(0.9319)$ \\
\hline$\Delta \mathbf{R}$ & $0.195667(0.3375)$ & $-0.585764(0.0963)^{*}$ & $-0.129930(0.7474)$ \\
\hline $\mathbf{R}^{2}$ & 0.470806 & 0.712404 & 0.057188 \\
\hline Sample & 6 & 6 & 6 \\
\hline
\end{tabular}


Table 4(B) : The Effect of Margin Requirements on Volatility - Margin Decreases

\begin{tabular}{|c|c|c|c|}
\hline & \multicolumn{3}{|c|}{ Dependent Variable: Volatility } \\
\hline $\begin{array}{c}\text { Independent } \\
\text { Variable: }\end{array}$ & 5-Day Interval & 10-Day Interval & 25-Day Interval \\
\hline Constant & $0.915692(0.2190)$ & $0.403332(0.3372)$ & $0.853289(0.1167)$ \\
\hline$\Delta \mathbf{M}$ & $0.00201024(0.9334)$ & $-0.0268604(0.1145)$ & $0.00695129(0.6804)$ \\
\hline$\Delta \mathbf{R}$ & $0.830912(0.0479)^{* *}$ & $1.56008(0.0064)^{* * *}$ & $1.20061(0.0960)^{*}$ \\
\hline $\mathbf{R}^{2}$ & 0.575924 & 0.802059 & 0.456208 \\
\hline Sample & 8 & 8 & 8 \\
\hline
\end{tabular}

*** indicates significant at 1 percent level

* indicates significant at 10 percent level

According to the liquidity effect, an increase in margin requirements makes margin trading more costly for all participants in the market and some investors will exit the market. The resulting lack of liquidity causes higher short-term volatility. Since relation between margin requirements and stock market volatility are not statistically significant, the finding provides no support for the existence of a liquidity effect associated with margins.

Brown and Forsythe (1974) statement could clarify the source of conflicting results. They argue that when the underlying distributions are non-normal, one should replace the mean with a "more robust estimate of central location" to compute the variances. Limited data on margin requirement could be another potential source of mixed result.

\section{Conclusion}

Since variance ratio (pre/post) is significantly less than 1 , we interpret this as supporting the margin requirement as a tool to reduce volatility. However, regression results did not reveal any statistically significant relation between margin requirements change and market volatility. Though we got a mixed result, these answers may give some comfort to the regulators that they may use margin requirements to trim down volatility in bourses in Bangladesh. indicates significant at 5 percent level

p-value is in parenthesis

\section{References}

Brockhaus, R. H. (1980). Risk taking Propensity of Entrepreneurs, Academy of Management Journal, 23(3), 509-520

Brown, M.B. and A.B. Forsythe, 1974, "Robust tests for the equality of variances," Journal of the American Statistical Association, 69, 364-367

Bucciol, A. and Miniaci, R. (2012). Household Portfolios And Risk Bearing Over Age And Time. University of Verona:

Busche, K. and Hall, C. D. (1988). An Exception to the Risk Preference Anomaly. The Journal of Business 61 (3), 337-346

Chowdhury, A. R (1997). Margin Requirements and Stock Market Volatility in Thailand. Applied Economics Letters 4, 83-87.

Figlewski, S., 1984, "Margins and market integrity: margin setting for stock index futures and options," Journal of Futures Markets, 4, 385-416.

Fortune, P. (2001). Margin Lending and stock market volatility, New England Economic Review 4(4), 1-25. 
French, K. R, Schwert, G. W., and Stambaugh R. F. (1987). Expected Stock Returns and Volatility. Journal of Financial Economics 19, 3-29.

Hardouvelis, G. A. and Theodossiou, P. (2002). The asymmetric relation between Initial Margin Requirements and Stock Market Volatility across Bull and Bear Markets. The Review of Financial Studies 15(5), 1525-1559

Moore, T., 1966, "Stock market margin requirements," Journal of Political Economy, 74, 158-167.

Hardouvelis, G. and Peristiani, S. (1989/1990). Do Margin Requirements Matter? Evidence from U.S. and Japanese Stock Markets. Federal Reserve Bank of New York Quarterly Review 14(4), 16.

Hardouvelis, Gikas A (1988). Margin requirements and stock market volatility. FRBNY Quarterly Review, Summer 1988.

Harlow, W. V. And Brown, K. C. (1990). Understanding and Assessing Financial Risk Tolerance: A Biological Perspective. Financial Analysts Journal.

Schoemaker, P. J. H. (1993). Determinants of RiskTaking: Behavioral and Economic Views. Journal of Risk and Uncertainty 6, 49-73.

Hsieh, D. A. and Miller, M. H. (1990). Margin Regulation and Stock Market Volatility. The Journal of Finance 45, 3-29.

Hsu, Y. (1996). Margin requirements and stock market volatility: Another look at the case of Taiwan. Pacific Basin Finance Journal, 4, 409-419

Kim, K. A. and Oppenheimer, H. R. (2002). Initial Margin Requirements, Volatility, and the Individual Investor: Insights from Japan. The Financial Review 37, 1-16

Krause, G. A. (2010). Agency Budgetary Risk Preferences under Context Dependent Uncertainty: An Analytical Inquiry, University of South Carolina
Kupiec, P. H. and Steven A. S. (1991). Animal Spirits, Margin Requirements, and Stock Price Volatility", The Journal of Finance 46, 717-731.

Lee, K. Y. (2009). Margin Requirements and Volatility: Evidence from Canadian Stocks. M.Sc in Management Thesis, Brock University.

Lee, S. B. and Yoo, T. Y. (1993). Margin regulation and stock market volatility: further evidence from Japan, Korea and Taiwan. Pacific-Basin Finance Journal 1, $155-174$.

Ricke, M. (2003). What is the link between margin loans and stock market bubbles? Institut fur creditwesen, University of Munster, Discussion paper 2003-01.

Salinger, M. A. (1989). Stock market margin requirements and volatility: Implications for regulation of stock index Futures. Journal of Financial Services Research 3, 121 -138.

Schwert, G. W. (1989). Margin Requirements and Stock Volatility. Journal of Financial Services Research 3, $153-164$.

\section{Authors' Profile}

Dr. A.F.M.Mainul Ahsan is working in Department of Economics, School of Business, Independent University, Bangladesh (IUB), Dhaka, Bangladesh. His email id is mainul@iub.edu.bd

Dr. Mohammad Osman Gani is working in Department of Economics, School of Business, Independent University, Bangladesh (IUB), Dhaka, Bangladesh. His email id is ganiosman@hotmail.com

Dr.Md.Bokhtiar Hasan is working in Research Development and Information Department, Dhaka Stock exchange, Dhaka Bangladesh. His email id is bokhtiar@dsebd.org 